\title{
Axial S
}

National Cancer Institute

\section{Source}

National Cancer Institute. Axial S. NCI Thesaurus. Code C103221.

Chirality axis based stereochemistry where, using the Cahn-Ingold-Prelog (CIP) priority rules, the priorities (from highest to lowest) of the substituent atoms exist in a counterclockwise direction. 